\title{
My unpublished research was scooped?

\author{
Misconduct reveals one way copyright preserves academic values
}

Editors' note: One of our recurring columnists, Nancy Sims, examines copyrightability with an analysis of an intriguing lawsuit. She also makes suggestions for how librarians can educate researchers about copyrightability as applied to scholarly publishing.

n many disciplines, researchers work simultaneously on closely related concepts or lines of research-related labs may be across the hall, or halfway around the world. While cross-pollination among researchers working on similar topics can be a positive force that drives research collaboratively forward, there is often competition among related researchers for resources, funding, and publication credits. It can be bitterly disappointing when one research team manages to publish on a new insight or discovery shortly before another competing team-even more so if the team that has been beaten to publication actually reached the new insight earlier.

Even so, most of the time, these kinds of "scoops" are not evidence of misconduct: among researchers working on closely related topics, it is not uncommon for more than one researcher or team to reach a new insight at nearly the same time. However, every once in a while, a scooped publication really does represent a "theft" of ideas.

This column will be exploring some of the implications of a lawsuit about "stolen" engineering research. All of the information I have comes from court opinions on a "motion for summary judgment."1 This kind of motion brought before a court explores the facts of a case deeply. A litigant who brings a motion for summary judgment does so because her or she think the facts and legal principles are so clear that it's not worth spending court resources to dig much deeper into the lawsuit.

In this case, the researchers who were accused of theft (the defendants) moved for summary judgment, so the court opinions relate the facts in the light most favorable to their accusers (the plaintiffs). The opinions treat all of the plaintiffs' factual allegations as true, as will I for this essay. But these may not be the exact facts of what really happened.

The lawsuit was brought by two engineering researchers at Northwestern University against two other researchers in another lab at Northwestern. Shih-Hui Chang was a graduate student in Seng-Tiong Ho's lab from 1997 to 2002. Early on, Ho developed a theoretical atomic model, completing the math for the model by 1999 . Yingyan Huang joined Ho's group in 2000. In 2001 another member of their group presented some of their concepts in a conference paper, which listed Ho, Chang, and Huang as coauthors. Huang's master's thesis, completed in 2002, contained more robust and detailed results of the research using this model. ${ }^{2}$

In 2002, Chang switched to Allen Taflove's research group. At some point, he asked Huang for a copy of her thesis, and some of the figures therein. Chang and Taflove published a symposium paper in $2003^{3}$ and a journal article in $2004^{4}$

Nancy Sims is copyright program librarian at the University of Minnesota, email: nasims@umn.edu

(0) 2016 Nancy Sims 
that used the model and figures from Huang's thesis without permission or attribution. Ho found out about the publications when a paper he submitted to a related journal was turned down for publication because it was too similar to the just-published article by Chang and Taflove.

Usually, these types of issues are handled through internal mechanisms enforcing academic integrity. There are currently no corrections listed to the 2003 symposium paper. An erratum for the 2004 article was published in 2006, and does reflect some level of direct apology: with only Taflove listed as the author, it states, "The subject paper that I co-authored with S.-H. Chang omitted a reference to the M.S. thesis by Y. Huang. I was not aware of [the thesis] at the time of the publication of [the paper], and regret the omission." 5 That erratum, and whatever other processes the institutions and organizations involved may have put into place, seem not to have assuaged the frustrations of Ho or Huang. ${ }^{6}$ They filed suit in 2007, alleging copyright infringement, and a number of other state law violations, against both Taflove and Chang.

And they lost.

This result may seem to some like manifest injustice. Chang and Taflove scooped Ho and Huang not by beating them to publication with original research, but by actually copying the earlier work of Ho and Huang, without acknowledgement. And the courts declined to do anything about it.

But the fact that the courts declined to do anything about it demonstrates one of the few ways that copyright law actually does function to preserve and promote the most important purposes of scholarly publishing. One of the bedrock principles of U.S. copyright law is that ideas are not copyrightable; copyright only covers the particular way an author expresses their ideas. The statute specifically excludes from coverage any "idea [...] concept, principle, or discovery." This is called the "idea-expression dichotomy." The Supreme Court has clarified that this principle also extends to exclude pure facts and data from copyright ownership, unless there is additional creative expression in their representation. ${ }^{8}$
Ho and Huang argued that their model, by representing a hypothetical situation, was a creative work, subject to copyright protection. The courts did not agree, stating "the Model strives to describe reality, and, as conceded at oral arguments, the value of the Model is its ability to accurately mimic nature." ${ }^{\prime \prime}$ The model expressed a fact about the world, and as such, wasn't eligible for copyright.

"Fine," some may say, "Maybe Chang and Taflove should have been able to talk about Huang and Ho's ideas, but they shouldn't have been able to copy their figures and equations."

That's where a very closely related copyright concept, the "merger doctrine," comes in. The law recognizes that when there is only one way, or only a very limited number of ways, to express a particular idea, then the unprotectable idea "merges" with the otherwise-protectable expression, and both are unprotected.

The Seventh Circuit explained how that applied in this case, stating:

Equations and figures are common components of mathematical science used to depict ideas. Although equations can be rearranged through the laws of mathematics, the substance of the equation nevertheless remains the same. Without any evidence that the Model could be expressed by equations and figures other than those used by the plaintiffs, we conclude that these equations and figures are 'required by' the Model, [...] and as such, are not subject to copyright. ${ }^{10}$

Threaded throughout the opinions issued by both the District and Circuit Courts, are suggestions that the case might have come out differently if Ho and Huang had perhaps retained a different legal counsel. All the opinions note fairly odd procedural failures. ${ }^{11}$ So it's possible Ho and Huang's legal counsel just didn't realize the weakness of copyright claims in this context. They did try some noncopyright lines of argument that were dismissed because they were too close to copyright concepts (and thus "preempted" by copyright law), but other noncopyright reasoning might have gotten through. 
Despite the unsatisfying result in this particular case, the idea-expression dichotomy is deeply essential to the functioning of scholarly publishing. Copyright terms now last for multiple generations. Preserving the exclusion of ideas from that control ensures that discourse and discovery can continue to move forward without the friction of fair use considerations, or permissions processes. The merger doctrine is also very important for research and scholarship because it ensures that, where there is a standard system or notation for specific kinds of concepts, control of the notation cannot grant control of the concepts. And even where standards are not at issue, it ensures that free exchange is maintained for ideas that can only be expressed in limited ways.

Both of these concepts can be surprising for some academics. Many scholars presume that the law protects ideas, concepts, facts, and data precisely because they are so essential to scholarly discourse. Sometimes scholars perceive the nonprotection of these things to be a judgment that they are not of any value. But many scholars are very receptive to the reframing that we've chosen to not protect these things precisely because they are of so much value that all need access. Scholars may also be reassured by a reminder that academic norms require that authors and creators receive credit for their work regardless of its ownership status.

Another useful way of contemplating the idea-expression dichotomy and merger doctrine is to imagine how research and scholarship would function in their absence: negotiating permissions to discuss ideas would greatly slow scholarly exchange. Both the permissions costs themselves, and their administration, would be costly. Authors might be able to use copyright law to control or stifle discussion of their research. Instruction and teaching would suffer. And imagine the chaos that would result if every researcher who wanted to work with a particular set of equations, or a particular functional representation of factual information, had to come up with a new way to express the same mathematical relationship or set of facts.

Many academic publishers today do behave as if the idea-expression dichotomy and merger doctrine don't exist for figures. They may require authors quoting figures from their own previous publications to get written permission from the prior publisher. This is an additional effort for the author, and sometimes even comes with a monetary price, which usually must be paid by the author. Some publishers are more flexible, allowing reproduction of figures without permission, with the understanding that it is fair use. But this fails to recognize that fair use isn't necessary if there is no copyright in a figure. Even for-profit or noneducational users will have an absolute right to reproduce it. Perhaps these practices are not surprising: almost all of the friction and costs that result from ignoring the idea-expression dichotomy and merger doctrine for academic figures land on individual authors, while publishers sometimes gain revenue by acting as though they are owners in these situations.

Although the idea-expression dichotomy and the merger doctrine can produce unpleasant results in outlier cases like that of the Hov. Taflove lawsuit, most of the time they function to the benefit of scholars and of research overall. When educating about copyright issues in scholarship, it is often worth the extra effort or time to at least introduce the idea that there are essential features of scholarship that are intentionally protected from copyright ownership.

\section{Notes}

1. Seng-Tiong Ho v. Taflove, 648 F.3d 489 (7th Cir. 2011); Seng-Tiong Ho v. Taflove, 696 F. Supp. 2d 950 (N.D. Ill. 2010).

2. Yingyan Huang, "Simulation of Semiconductor Materials Using FDTD Method" (Master's thesis, Northwestern University, 2002).

3. Shih-Hui Chang, Hui Cao, and Allen Taflove, "Four-level two-electron FDTD model of lasing action in a semiconductor," Antennas and Propagation Society International Symposium 2003, vol 4 (2003): 382-385, doi: 10.1109/ APS.2003.1220201.

4. Shih-Hui Chang and Allen Taflove, "Finitedifference time-domain model of lasing action in a four-level two-electron atomic system," Opt. Express 12 (2004): 3827-3833, doi: 10.1364/ OPEX.12.003827.

(continues on page 301) 
on the subjects I was studying, it was one of the very few buildings that had reliable climate control and Internet access. For these scholarly and practical reasons, I encourage students to visit their host libraries. I also tell students how helpful it was for me to have access to my home institution's library during my studies abroad. In the middle of adjusting to so many new things, it was comforting to work with something as familiar as my home library's website. Additionally, to the students that will be completing their studies in another language, I confess that I would occasionally boost my essays' word counts by quoting English-language resources and then translating them into Spanish. Again, scholarly and practical.

In this spirit of candor, I also touch on the oft-repeated subject of safety with the students. I recount to them how, while my time abroad was wonderful and life-changing, it did have a sad moment when I was careless about watching my belongings and had my wallet stolen. That unfortunate incident, which happened in the last weeks of my studies, put a damper on my remaining time in Mexico and my return to the United States.

Of course, students are lectured on end about safety before and during their study abroad, but these talks are sometimes impersonal and overly broad. It is my hope that hearing about one specific incident involving a person they know will help them keep their safety in mind, where it always needs to be.

\section{Conclusion}

It is very rewarding to be able to use my experience as a former study abroad student, in addition to my knowledge as a librarian, to help students have the best study abroad experience possible. To any librarian hoping to do the same, I would recommend the following:

1. Talk to many departments. Study abroad offices go by many names. I found the study abroad office for one campus through a connection with a Foreign Languages faculty member. Some departments, such as business schools, often have their own programs to travel to countries with emerging economies. Talk to them all. Let them know that you can help students and faculty, even when they are out of the country.

2. Don't assume anyone knows what they (or you) can do. Many study abroad faculty are just as surprised as their students when they learn everything that remote access can do, or all the ways they can contact librarians. Even those that know about library services may not realize that these services are available globally.

3. Think like a bomesick student. When promoting your own library and whatever host library students may have access to, talk about libraries as a source of stability and familiarity. It doesn't matter whether students visit your library's page for a particular resource or a taste of home. It doesn't matter whether they visit a new library for foreign material or the air conditioning.

4. Make it personal. Finally, I would recommend any librarian who has also had a study abroad experience to contemplate what they learned during that time and how it may benefit future generations of travelers. Study abroad experiences are incredibly personal in the impact they have on students, but they are universal in their ability to broaden students' minds. It is only fitting that libraries and librarians are part of the journey. $\boldsymbol{n}$

\section{("My unpublished research was scooped?" continues from page 298)}

5. Allen Taflove, "Finite-difference timedomain model of lasing action in a four-level two-electron atomic system: Erratum," Opt. Express 14 (2006): 1702-1702, doi: 10.1364 /OE.14.001702.

6. The District Court's opinion includes quotations from a plagiarism inquiry committee at Northwestern (Ho v. Taflove, 696 F. Supp. 2d at 955), which suggests the internal mechanisms did at least come into play.

7. 17 U.S.C. $\$ 102$.

8. Feist Publications, Inc., v. Rural Telephone Service Co., 499 U.S. 340 (1991).

9. Ho v. Taflove, 648 F.3d, at 498.

10. Ho v. Taflove, 648 F.3d, at 499.

11. Ho v. Taflove, 696 F. Supp. $2 \mathrm{~d}$ at 958 (noting counsel filed a motion of a type that doesn't exist). 